\title{
Acute Adverse Effects of Formaldehyde Treated Cadaver on New Innovative Medical Students and Anatomy Staff Members in the Dissection Hall at Wollo University, Northeast Ethiopia
}

This article was published in the following Dove Press journal:

Advances in Medical Education and Practice

\section{Chalachew Tiruneh (iD}

Department of Anatomy, College of Medicine and Health Sciences, Wollo University, Dessie, Ethiopia
Correspondence: Chalachew Tiruneh Department of Anatomy, College of Medicine and Health Sciences, Wollo University, Po Box: I I45, Dessie, Ethiopia Tel +251920245474

Email Chalachewtiruneh19@gmail.com
Introduction: Formaldehyde is the most frequently used chemical for the preservation of a cadaver. However, its toxicity in the dissection hall is frequently ignored.

Objective: To assess the acute adverse effects of formaldehyde treated cadaver on preclinical new innovative medical students and anatomy staff members in the dissection hall at Wollo University, Ethiopia.

Methods: This institutional-based cross-sectional study was carried out from January 20 to February 25, 2020. A total of 88 study participants were surveyed at the department of Human Anatomy, Wollo University, Ethiopia. The participants were those who were exposed to formaldehyde vapors during the dissection of a cadaver in the dissection hall. A selfadministered questionnaire which contains the clinical symptoms observed after formaldehyde exposure was used to collect data. The data were entered into EpiData version 4.2 and then exported to SPSS Version 21 for analysis. Finally, the data were expressed in texts, tables, and figures.

Results: The study comprised 84 (95.5\%) male and 4 (4.5\%) female. In this study, the top three most common acute adverse effects of formaldehyde during dissection of a cadaver in the cadaver room were unpleasant smells, Tiredness/dizziness, and watering of eyes (lacrimation), each accounted for 64 (72.7\%), 39 (44.3\%) and 35 (39.8\%), respectively. The other acute adverse effects were running nose with tingling sensation 27 (30.7\%) followed by lack of concentration $24(27.3 \%)$ and headache $22(25 \%)$.

Conclusion: In dissection hall, preclinical medical students and instructors are at high risk to develop various acute adverse symptoms of formaldehyde. Therefore, a free-aldehyde preservation solution should be assumed to prevent its toxicity.

Keywords: adverse effects, cadaver embalming, formaldehyde, innovative medicine, Wollo University

\section{Introduction}

Formaldehyde was discovered in 1867 by the British chemist, August Wilhelm Von Hofmann. It is a simple aldehyde with the molecular formula $\mathrm{CH}_{2} \mathrm{O}{ }^{1}$ It is a colorless, flammable gas, very soluble in water; the aqueous solution (about $37 \%$ formaldehyde) is called formalin. This chemical substance is commonly used in a different setting like in hospitals and medical colleges as a disinfectant, embalming solution, and preservative. It is also used in the plastic 
and wood industries. Although formalin is very essential in a different field, its adverse effects are not yet observed. $^{2}$

In medical schools, a corpse is preserved via the infusion of chemical substances that include formalin (which contains formaldehyde), carbolic acid, alcohol, dye, and glycerin. These substances have a particular role and they are usually infused through the internal carotid arteries or femoral arteries. In dissection hall, the vapor of formaldehyde from the preserved corpse, preservative fluid, could adversely affect instructor's and medical student's health. ${ }^{3,4}$ It enters into the systems of the body via inhalation or when it comes in contact with skin. ${ }^{5}$

A cadaver is preserved using different embalming chemicals in different countries for a century. ${ }^{6}$ However, the most recent chemicals used for embalming of cadaver are alcohol, glycerin, phenol, and formaldehyde. In the current study setting, the chemicals and their proportion used for cadaver preservation are; $5.5 \mathrm{~kg}$ phenol, 5.5 liters of formaldehyde, 30 liters of alcohol, 14 liters of glycerin plus 55 liters of $\mathrm{H}_{2} \mathrm{O}$; then, a total of 110 liters of solution used for three cadavers. One cadaver is injected 25 liters continuously and after 24 hours another 5-10 liters is added.

Formaldehyde has been described to cause acute and chronic health-related problems. The most common acute adverse effects are headache, upper respiratory tract, skin, and irritation of eyes which are related to high concentration exposure. $^{7}$

The adverse effect of formaldehyde is increased as the amount of concentrations increased and when it becomes at room temperature due to its volatility property. ${ }^{8}$ Formaldehyde is an irritant compound that irritates the mucous membrane of the nose, throat, and eyes. Because of the toxic effect of formaldehyde exposure, embalmers, anatomists, laboratory technicians, and medical students are among the people who had a high risk of the effect of formalin toxicity. ${ }^{9}$

Despite this adverse effect on personnel while doing dissection in the dissection room, there is limited research conducted in developing countries including Ethiopia. As a result of a limited investigation conducted, the innovative medical students and staff members do as usual without fearing the side effects. Therefore, the study was aimed to identify the major acute adverse effect of formaldehyde treated cadaver and to recommend the major preventive measure during cadaver dissection in the dissection hall.

\section{Methods and Materials}

\section{Study Area}

The study was conducted in Wollo University, school of medicine, anatomy department. In the anatomy department, there is only one dissection room. In addition to the dissection function of the room, it is also used for the storage of cadaver and preserved organs. The room is located on the second floor of the building. The room has three windows, which represent natural ventilation. There are no other artificial ventilation devices in the dissecting room. The average duration of exposure for each student in the dissection hall was 4 hours per week.

The university is found in Dessie town, located $401 \mathrm{~km}$ from Addis Ababa, the capital city of Ethiopia, and $478 \mathrm{~km}$ far from Bahir Dar, the capital city of Amhara regional state. The university has a college of medicine and health sciences. This college has a school of public, school of nursing and midwifery, and school of medicine. Under the school of medicine, there are three departments; medicine, anesthesia, and biomedical science (anatomy, physiology, and biochemistry).

\section{Study Design and Period}

Institutional-based cross-sectional study design was employed from January 20 to February 25, 2020.

\section{Source and Study Population}

The source population was all new innovative medical students and anatomy staff members, whereas the study population was all preclinical I and II new innovative medical students, and anatomy staff members who were exposed to formaldehyde and full fill inclusive criteria at the time of the study.

\section{Sample Size and Sampling Techniques}

Since there were a limited number of people $(n=93)$, the entire study participants were included in the study. Out of this study participants, two of them were not voluntary and three of them were absent during data collection. As a result, a total of 88 sample sizes were used in this study.

\section{Eligibility Criterion}

The PC I and PC II innovative medical students and anatomy staff members, who gave their consent towards the study, were included in the study. However, those who are involuntary, absent during the data collection period, seriously ill, and having previous know diseases like 
a respiratory problem (asthma, $\mathrm{TB}$, etc.), known to allergic to formalin, eye problem, and those who have a neurological problem were excluded from the study.

\section{Data Collection Tool and Procedures}

A self-administered questioner was used to collect data. The tool was adapted from the previously published literatures. The tool contains written consent forms, sociodemographic characteristics, acute adverse symptoms of formaldehyde in the dissection hall such as watering of eyes, redness of eyes, running nose with a tingling sensation, irritation of the throat, cough, difficulty in breathing, tiredness/dizziness, skin problems (itching, sore skin on hands, burning sensation), lack of concentration, unpleasant smell, headache, disturbance of sleep, nausea, vomiting, abdominal pain, and reproductive disorder (menstrual disorder). Furthermore, it also contains personal-protective equipment usage history to prevent the adverse effects of formaldehyde. Finally, the data were collected by the biochemistry staff. Timely supervision was undertaken by the principal investigator (PI) during the data collection period.

\section{Data Quality Control}

To keep data quality, preparation was assumed for data collectors. After this, Pretest of the questionnaire was conducted on $10 \%$ of the sample size in Debre Berhan University a week before the actual survey, and the necessary modification was done accordingly. The data were collected in their classroom by two biochemistry staff. The principal investigator had carried out supervision during the data collection period to check data completeness and reliability. The consistency and representativeness of data were maintained by including merely complete data of study subjects in the study period.

\section{Data Processing and Analysis}

The data were checked after data collection for its completeness. Then, data were entered into Epi-Data version 4.2 and then exported to SPSS Version 21 for analysis. The data were described in the text, table, and graphs.

\section{Ethical Consideration}

Ethical clearance was obtained from the Department of Research Ethics Review Committee (DRERC) of Wollo University. The purpose and objective of the study were explained to study participants, and they were informed to withdraw from the study at any time and/or to refrain from responding to questions if they were not interested to participate for any reason. After clearly explaining the purpose of the study, written informed consent was obtained from each study participant. And also, the confidentiality of study participants' information was maintained by taking the data anonymously. After data collection, the raw data were secured and was not accessed by anyone except the principal investigator and personal identifiers to keep confidentially.

\section{Results}

\section{Sociodemographic Characteristics}

Out of 93 selected study participants, only 88 (94.6\%) study participants were filled a self-administered questioner. The rest of the five study participants did not participate in the study. Two $(n=2)$ of them were involuntary, whereas three participants were absent during data collection $(n=3)$.

Most of the study participants' ages were in the range of 29-33 followed by 24-28 years, each accounted for 49 (55.7\%) and 35 (39.8\%), respectively. The study comprised $84(95.5 \%)$ male and $4(4.5 \%)$ female. Regarding the residence of the participants, most of them came from $52(59.1 \%)$ rural areas. Furthermore, the majority of respondents' religion was 42 (47.7\%) Orthodox Christian followed by 35 (39.8\%) Muslim religion followers (Table 1).

\section{Acute Adverse Effects of Formaldehyde Treated Cadaver}

During dissection of a cadaver, there were many of formaldehyde related symptoms which were reported by new innovative medical students and anatomy staff members. Amongst the top three acute adverse effects of formaldehyde during dissection of a cadaver were unpleasant smells, tiredness/dizziness, and watering of eyes (lacrimation) each accounted for 64 (72.7\%), 39 (44.3\%), and 35 (39.8\%), respectively. The other acute adverse effects were running nose with tingling sensation 27 (30.7\%), lack of concentration $24(27.3 \%)$, and headache $22(25 \%)$. The least reported symptom was a reproductive disorder (menstrual disorder) 1 (1.1\%) (Table 2).

\section{Factors Affecting the Practice of Respondents}

The possible associated factors for the occurrences of these acute symptoms in the dissection hall were due to 
Table I Sociodemographic Characteristics of Preclinical New Innovative Medical Students and Anatomy Staff Members in Wollo University, Ethiopia

\begin{tabular}{|c|c|c|c|}
\hline Variables & & Frequency & Percentage \\
\hline \multirow[t]{3}{*}{ Age (years) } & $24-28$ & 35 & 39.8 \\
\hline & $29-33$ & 49 & 55.7 \\
\hline & $>34$ & 4 & 4.5 \\
\hline \multirow[t]{2}{*}{ Gender } & Male & 84 & 95.5 \\
\hline & Female & 4 & 4.5 \\
\hline \multirow[t]{4}{*}{ Religion } & Orthodox & 42 & 47.7 \\
\hline & Muslim & 35 & 39.8 \\
\hline & Protestant & 10 & 11.4 \\
\hline & Others & I & I.I \\
\hline \multirow{4}{*}{$\begin{array}{l}\text { Educational } \\
\text { background }\end{array}$} & Health science & 83 & 94.2 \\
\hline & Applied science & 2 & 2.2 \\
\hline & Agriculture & 3 & 3.3 \\
\hline & Veterinary & I & I.I \\
\hline \multirow[t]{2}{*}{ Residence } & Urban & 36 & 40.9 \\
\hline & Rural & 52 & 59.1 \\
\hline \multirow[t]{5}{*}{ Ethnicity } & Amhara & 63 & 71.6 \\
\hline & Oromo & 10 & 11.4 \\
\hline & Tigre & 8 & 9 \\
\hline & Gurage & 5 & 5.7 \\
\hline & Others & 2 & 2.3 \\
\hline
\end{tabular}

dissecting a cadaver without using personal protective equipment such as face masks, gloves, and goggles. The main causes for not using personal protective equipment in the dissection room were lack of resources 57 (64.7\%) followed by lack of knowledge 30 (34.1\%) (Figure 1).

\section{Discussion}

Cadaver had been a key for centuries to teach human gross anatomy for medical students in anatomy laboratories. ${ }^{10}$ To prevent decomposition; a cadaver was preserved via different embalming chemical. Formaldehyde was the most frequently used embalming chemicals for the preservation of cadaver for a period of time. The presence of this chemical had the potential to be vapor out from cadaver while dissecting in dissection hall. As a result, most medical students, instructors, and laboratory technicians
Table 2 Acute Adverse Effects of Formaldehyde treated cadaver on Preclinical New Innovative Medical Students and Anatomy Staff Members in the Dissection Hall at Wollo University, Ethiopia

\begin{tabular}{|l|l|l|}
\hline Symptoms & Frequency & Percentage \\
\hline Watering of eyes & 35 & 39.8 \\
Redness of eyes & 19 & 21.6 \\
Running nose with tingling sensation & 27 & 30.7 \\
Irritation of throat & 13 & 14.8 \\
Cough & 9 & 10.2 \\
Difficulty in breathing & 3 & 3.4 \\
Tiredness/dizziness & 39 & 44.3 \\
Skin problems (Itching, sore skin on & 17 & 19.3 \\
hands, burning sensation) & & \\
Lack of concentration & 24 & 27.3 \\
Unpleasant smell & 64 & 72.7 \\
Headache & 22 & 25 \\
Disturbance of sleep & 20 & 22.7 \\
Nausea & 17 & 19.3 \\
Vomiting & 8 & 9.1 \\
Abdominal pain & 3 & 3.4 \\
Reproductive disorder (menstrual & 1 & 1.1 \\
disorder) & & \\
\hline
\end{tabular}

inhaled this chemical unknowingly and they develop formaldehyde-related symptoms such as fatigue, headache, and irritation of the nose, throat, and eyes. ${ }^{11}$

In the current study, the author had investigated several acute adverse effects of formaldehyde during dissecting a cadaver in the dissection hall. The acute adverse effects of formaldehyde were unpleasant smell (72.7\%), tiredness/dizziness $(44.3 \%)$, watering of eyes $(39.8 \%)$, running nose with a tingling sensation (30.7\%), lack of concentration (27.3\%), headache (25\%), disturbance of sleep (22.7\%), redness of eyes (21.6\%), nausea (19.3\%), skin problems (19.3\%), irritation of the throat (14.8\%), cough (10.2\%), vomiting (9.1\%), abdominal pain (3.4\%), difficulty in breathing (3.4\%), and menstrual disorder $(1.1 \%)$, respectively, from the highest prevalence to the lowest. In dissection hall, the majority of the respondents were not used personal protective equipment such as wearing face masks, gloves, and goggles regularly in the dissection hall. This might be the main reason for developing these acute adverse symptoms of formaldehyde vapors. This result was supported by many studies. ${ }^{4,12,13}$

In the current study, the top most common reported acute adverse effects of formaldehyde while dissecting a cadaver was the unpleasant smell (72.7\%) followed by tiredness/ dizziness (44.3\%). This finding was consistent with a study carried out in Ethiopia by Hagos et al, who revealed that the 


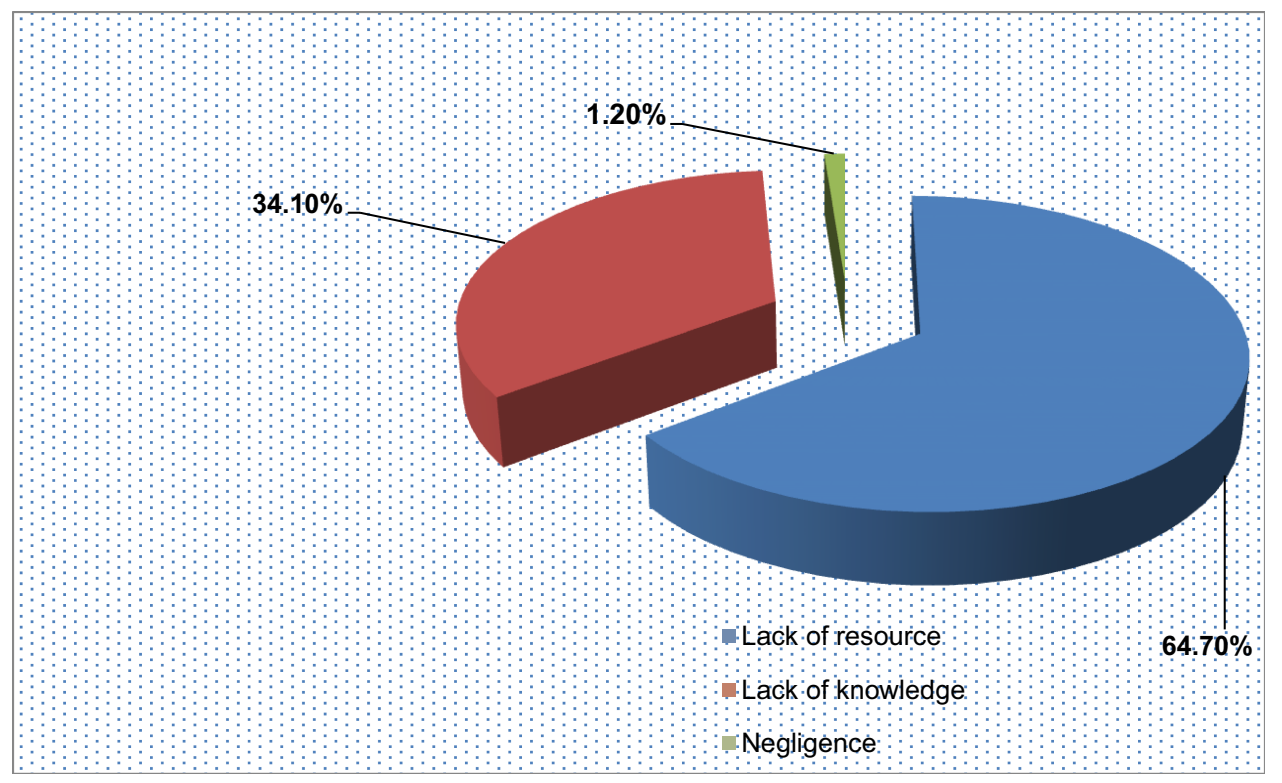

Figure I Factors not using personal protective equipment's by preclinical new innovative medical students and anatomy staff members in the dissection hall at Wollo University, Ethiopia.

most common toxic effect of formalin on the medical students was the unpleasant smell (84.4\%). ${ }^{14}$ Another study conducted in India by Abhijeet and Mukul; also revealed that the most commonly reported symptoms related to the effects of formalin were the unpleasant smell (30\%) followed by Unusual tiredness or dizziness $(25.3 \%){ }^{3}$

Moreover, Kundu and Gangrade conducted a study on Indian medical students and found that the most common reported symptom among medical students was unpleasant smell (94.68\%). ${ }^{15}$ Another study conducted in Egypt by Elshaer and Mahmoud; also in agreement with the current study; he found that the most frequently reported symptoms by medical students were unpleasant smell (91.2\%) followed by itching in the eyes $(81.3 \%) .{ }^{16}$ And also, another study conducted on toxic effects of formalin in Egypt by Ahmed et al; found that the majority of students were suffered from unpleasant smell (79.6\%) followed by eye irritation (63.6\%). ${ }^{17}$

In contrast to the current study, a study which was conducted in India by Nisa et al revealed that the most common reported symptoms related to formalin by medical students were watering of eyes (88.1\%) followed by running nose with a tingling sensation in the nose $(30.7 \%)$. He also investigated that watering of the eye was the first reported symptom to develop in most medical students $(74.8 \%) .{ }^{13}$ This discrepancy with the current study might be due to the sample size differences in which the current study sample size was small as compared to it. Furthermore, the current study also had contradiction with a study conducted in Libya by Alnagar et al; he conducted a study on adverse effects of formaldehyde exposure and found that students had a high reported prevalence of nasal itching 78 (75\%) followed by eyes burning 78 (75\%) symptoms. ${ }^{18}$ The difference in the symptom could be due to the difference in sample size usage and personal protective equipment usage during dissection as compared to the current study.

On the other hand, the present had consistency with a study carried out in Nigeria by Onyije and Avwioro; he studied the excruciating effects of formaldehyde exposure to students and found that $77 \%$ of the students were strongly affected by the unpleasant smell of formaldehyde followed by the runny or congested nose $(57 \%){ }^{19}$

\section{Conclusion}

The current study investigated that the vapors of formaldehyde during cadaver dissection in the dissection hall have many adverse health effects on students as well as anatomy staff members. The top three most common acute adverse effects of formaldehyde during dissection of a cadaver in the cadaver hall were unpleasant smells, tiredness/dizziness, and watering of eyes (lacrimation). Despite the adverse effects, formaldehyde is still used for the preservation of cadaver because of its low cost and effectiveness. Moreover, the majority of medical students and anatomy staff members did not wear personal protective equipment (PPE) such as face masks, eye goggles, and gloves in the anatomy 
dissection hall. These make us more vulnerable to the acute adverse effect of formaldehyde vapors in the dissection hall.

\section{Recommendations}

- The higher authorities of the university and anatomists should seek alternative less hazardous chemicals to preserve human cadavers.

- The ventilation systems of the anatomy dissection hall should be amended.

- The awareness of medical students and anatomy staff members about the adverse effects of formaldehyde should be raised.

- All peoples who enter the dissection hall should be encouraged to use personal protective equipment such as aprons, face masks, eye goggles, and gloves.

- The formaldehyde concentration level in the air should be continuously monitored in the dissection hall.

- Formaldehyde concentration in embalming solution should be reduced.

- Free-aldehyde preservation solution should be thought over to prevent its toxicity.

- Furthermore, a study should be conducted on a larger scale on its acute and chronic toxicity.

\section{Data sharing Statement}

The datasets used and/or investigated during the current study are available from the corresponding author on reasonable request.

\section{Ethical Approval and Consent to Participate}

Ethical clearance was obtained from the Department of Research Ethics Review Committee (DRERC) of Wollo University, and a supportive letter was obtained from Wollo University, College of medicine and health sciences, department of pre-clerkship. The purpose and objective of the study was explained to study participants, and they were informed to withdraw from the study at any time and/or to refrain from responding to questions if they were not interested to participate for any reason. Then, after clearly explaining the purpose of the study, written informed consent was obtained from each study participant. Finally, data were collected and Confidentiality of information was maintained through taking the data anonymously. The author confirms that this study was conducted in accordance with the Declaration of Helsinki.

\section{Acknowledgments}

The author thanks Wollo University for providing ethical clearance and a supportive letter for this research preparation. The most sincere gratitude also goes to new innovative medical students and anatomy staff members for their kind participation in this study. Finally, the author also thanks the data collectors for their cooperation.

\section{Funding}

No fund was received to conduct this study.

\section{Disclosure}

The author reports no conflicts of interest for this work.

\section{References}

1. Loprieno N. International Agency for Research on Cancer (IARC) monographs on the evaluation of carcinogenic risk of chemicals to man: relevance of data on mutagenicity.Mutat Res 1975; 31 (3): 210. doi:10.1016/0165-1161(75)90092-8

2. Chia SE, Ong CN, Foo SC, Lee HP Medical students' exposure to formaldehyde in a gross anatomy dissection laboratory. $\mathrm{J} \mathrm{Am} \mathrm{Coll}$ Health. 1992; 41 (3):115-119. doi:10.1080/07448481.1992.9936310

3. Abhijeet Y, Mukul YA Study of the effects of formalin on first year MBBS students. Sch J Appl Med Sci. 2014; 2 (5B):1588-1590.

4. Lakchayapakorn K, Watchalayarn P Formaldehyde exposure of medical students and instructors and clinical symptoms during gross anatomy laboratory in Thammasat University. J Med Assoc Thai. 2010; 93 (Suppl 7):S92-8.

5. Binawara BK, Rajnee CS, Mathur K, Sharma H, Goyal K Acute effect of formalin on pulmonary function tests in medical students. Pak J Physiol. 2010; 6 (2):8.

6. Brenner E Human body preservation-old and new techniques. $J$ Anat. 2014; 224 (3):316-344. doi:10.1111/joa.12160

7. Kim CW, Song JS, Ahn YS, et al. Occupational asthma due to formaldehyde.Yonsei Med J. 2001;42 (4):440-445. doi:10.3349/ ymj.2001.42.4.440

8. Songur A, Akpolat N, Kus I, Ozen OA, Zararsiz I, Sarsilmaz M The effects of the inhaled formaldehyde during the early postnatal period in the hippocampus of rats: a morphological and immunohistochemical study. Neurosci Res Commun. 2003;33 (3):168-178. doi:10.1002/ nrc. 10093

9. Dixit D Role of standardized embalming fluid in reducing the toxic effects of formaldehyde. Indian J Med Forensic Med Toxicol. 2008;2 (1):33-39.

10. Cornwall J, Stringer MD The wider importance of cadavers: educational and research diversity from a body bequest program. Anat Sci Educ. 2009;2(5):234-237. doi:10.1002/ase.103

11. Mori M, Hoshiko M, Hara K, Saga T, Yamaki K, Ishitake T Changes in subjective symptoms and allergy state among medical students exposed to low-level formaldehyde 6 months after completion of a gross anatomy dissection course. Environ Health Prev Med. 2013;18 (5):386-393. doi:10.1007/s12199-013-0337-7

12. Kunugita N, Nakashima T, Kikuta A, Kawamoto T, Arashidani K Exposure to formaldehyde during an anatomy dissecting course. J UOEH. 2004;26 (3):337. doi:10.7888/juoeh.26.337

13. Nisa G, Shah BA, Shahdad S, Jan N, Samoon S, Ahmad S Acute toxic effects of formalin on first year MBBS students during dissection in Gross anatomy laboratory. J Dent Med Sci 2016; 15(8): 56-59. doi:10.9790/0853-1508115659 
14. Hagos S, Gebeya D, Teklay A Effects of formalin toxicity among preclinical i medical students, Adigrat University, Ethiopia. Int J Sci. 2018; 7 (1):39-42. doi:10.18483/ijSci.1479

15. Kundu S, Gangrade P Study of the toxic effects of formaldehyde vapours within dissection hall on the first year Indian medical students. Int J Anat Res. 2015; 3 (2):1179-1190. doi:10.16965/ ijar.2015.195

16. Elshaer NS, Mahmoud MA Toxic effects of formalin-treated cadaver on medical students, staff members, and workers in the Alexandria Faculty of Medicine. Alexandria J Med. 2017;53(4):337-343. doi:10.1016/j.ajme.2016.11.006
17. Ahmed YA, Abdelsabour - Khalaf M, Abdelrahim E, Ghallab A. Toxic effects of formalin on the medical students of South Valley University following repeated exposure at the anatomy laboratories. SVU Int J Vet Sci. 2020; 3 (1):80-86. doi:10.21608/svu.2020.24069.1042

18. Alnagar FA, Shmela ME, Alrtib AM, Benashour FM, Buker AO, Abdalmula AM Health adverse effects of formaldehyde exposure to students and staff in gross anatomy. Int J Sci Res Manag 2018: 06 02: 27-36. doi:10.18535/ijsrm/v6i2.mp02

19. Onyije FM, Avwioro OG Excruciating effects of formaldehyde exposure to students in gross anatomy dissection laboratory. Int $J$ Occup Environ Med 2012; 3: 92-95

\section{Publish your work in this journal}

Advances in Medical Education and Practice is an international, peerreviewed, open access journal that aims to present and publish research on Medical Education covering medical, dental, nursing and allied health care professional education. The journal covers undergraduate education, postgraduate training and continuing medical education including emerging trends and innovative models linking education, research, and health care services. The manuscript management system is completely online and includes a very quick and fair peer-review system. Visit http://www.dovepress.com/testimonials.php to read real quotes from published authors. 